\title{
ANALISIS PROSES BISNIS DAN KEBUTUHAN SISTEM INFORMASI RENDAL PRODUKSI DI INDUSTRI FARMASI: STUDI KASUS PT. TNF
}

\author{
Jimmy Robot ${ }^{1)}$, Nancy Tuturong ${ }^{2)}$ \\ ${ }^{1)}{ }^{2)}$ Program Studi Teknik Informatika, Fakultas Teknik, Universitas Sam Ratulangi, \\ Jl. Kampus UNSRAT Bahu, Manado, 95115, Indonesia \\ E-mail: jimmy.robot@unsrat.ac.id
}

\begin{abstract}
Abstrak
Suatu industri manufaktur yang berorientasi pada profit memerlukan alat bantu agar bisnisnya dapat menjalankan proses eksekusi manufaktur lebih baik. Industri farmasi pun tak luput dari pola keberhasilan seperti ini. PT. TNF merupakan salah satu industri farmasi yang berorientasi pada pasar, dengan menciptakan produk-produk yang makin kompleks, sesuai dengan keinginan pasar. Sebagai salah satu industri yang bergerak dalam bisnis obatobatan ini membutuhkan sistem informasi agar tercapainya tujuan organisasi untuk meningkatkan efisiensi perusahaan, daya saing dan inovasi produk yang bertaraf internasional. Salah satu peranan vital dalam bisnis industri ini adalah proses dalam Unit Produksi dan PPIC sebagai pengendalian perencanaan produksi serta pengadaan sebagai pengelola lalu lintas material dan barang jadi/produk. Sebagai dasar pertimbangan inilah, maka penulis mengangkat masalah analisis proses bisnis dan kebutuhan sistem informasi perencanaan dan pengendalian (Rendal) Produksi berbasis agent di PT. TNF sehingga pengorganisasian sumberdaya perusahaan untuk menghasilkan produk sesuai dengan kebutuhan konsumen. Untuk menggambarkan arsitektur sistem sesuai konteks pembahasan digunakan UML agar memudahkan analisis dan pengembangan. Kesimpulan yang dapat diambil adalah sistem rendal produksi yang dirancang dapat membantu mengatasi permasalahan pada unit operasi PPIC dan rendal Produksi yang ditemui di PT.TNF.
\end{abstract}

Kata Kunci: Agent, GAI, Unit Produksi, UML, PPIC, Sistem Rendal Produksi

\section{Pendahuluan}

Salah satu indikator berhasilnya industri yang berorientasi pada profit yang besar tak lepas dari terciptanya efisiensi cost dalam melaksanakan manajemen operasi dari suatu organisasi manufaktur. Secara umum suatu keberhasilan era manufaktur yang modern sekarang ini tidak lepas dari peran penting sistem informasi/ teknologi informasi yang bergerak dari suatu program peningkatan efisiensi, keefektifan sampai menciptakan inovasi baru untuk mencapai keunggulan bersaing. Suatu industri farmasi pun tak luput dari pola keberhasilan seperti ini. PT. TNF merupakan salah satu industri farmasi yang berorientasi pada pasar, dengan menciptakan produk-produk yang makin kompleks, sesuai dengan keinginan pasar. Sebagai salah satu industri yang bergerak dalam bisnis obat-obatan ini membutuhkan alat bantu agar proses bisnisnya mengalami perkembangan yang signifikan terhadap pencapaian tujuan organisasi. Salah satu peranan vital dalam bisnis industri ini adalah proses dalam Unit Produksi dan PPIC sebagai pengendalian perencanaan produksi serta pengadaan sebagai pengelola lalu lintas material dan barang jadi/produk. Unit ini melayani produksi yang dinginkan oleh Unit Bisnis yang cenderung customized. Oleh sebab itu, Unit Produksi dan PPIC dituntut memiliki fleksibilitas dalam proses manufakturnya.

Salah satu pengembangan model sistem cerdas yang berperan dalam sistem informasi manufaktur adalah multi-agent system (MAS). MAS merupakan kumpulan sistem informasi berbasis agent yang memungkinkan user dapat mendelegasikan tugas kepadanya secara mandiri.

Sebagai dasar pertimbangan inilah, maka penulis mengangkat masalah perancangan sistem informasi perencanaan dan pengendalian (Rendal) Produksi berbasis MAS di PT. TNF sehingga pengorganisasian sumberdaya perusahaan untuk menghasilkan produk sesuai dengan kebutuhan konsumen, dan meninjau kembali proses tersebut agar pengelolaan operasional dari segi teknis dan non teknis (time, cost,dan decision making) menjadi lebih efisien.

Penulisan ini akan membahas: 
1) Bagaimana rancangan sistem multi agent yang sesuai dengan sistem perencanaan dan pengendalian produksi di PT. TNF?

2) Bagaimana model perangkat lunak berbasis agent sebagai alat bantu untuk menyusun dan menginformasikan jadual produksi dan status lantai produksi di Unit Produksi?

\section{Sistem Komputerisasi Manufaktur}

Dalam melakukan proses Rendal Produksi dalam industri manufaktur tak terlepas dari sistem corporate yang terbentuk di dalam sistem tersebut.

Semua bagian tingkatan di atas memiliki alur-alur informasi. Pada tingkatan pengendalian level rendah, informasi yang diberikan sangatlah bergantung pada waktu dimana setiap detik kegagalannya akan sangat berharga sekali. Sedangkan informasi yang sama pada tingkatan yang lebih tinggi dapat digunakan sebagai control kualitas beberapa hari atau minggu kemudian. Dari penjelasan di atas dapat dilihat kepentingan data-data di atas bagi kebutuhan eksekusi sistem Rendal Produksi sebagai komponen penghubung antara unit-unit fungsional (cell, workstation dan equipment) dan unit strategis (corporate management, finance, marketing dan sales, research dan development).

\section{Analisa dan Perancangan Berorientasi Objek}

Analisa dan perancangan berorientasi objek adalah pendekatan perancangan (khususnya untuk sistem informasi) dengan memandang sistem terdiri atas objek-objek. Keunggulan utama dari pendekatan ini adalah objek perangkat lunak yang dirancang bisa digunakan secara berulang atau dimodifikasi sesuai kebutuhan sehingga proses perancangan ulang atau perawatan sistem lebih mudah (Dennis et.al, 2005).

Secara umum ada dua langkah untuk membuat model objek yaitu:

1) Menemukan serta mengidentifikasi objek bisnis

2) Mengorganisasikan objek dan mengidentifikasi hubungan antar objek.

\section{Pengembangan dengan Sistem Agent}

Konsep agent sudah dikenal lama dalam bidang Artificial Intelligence (AI), tepatnya dikenalkan oleh seorang peneliti bernama Carl Hewitt dengan concurrent actor model-nya pada tahun 1977. (Nwana, 1996).

Definisi software agent sebagai (Wahono, 2003): Suatu entitas software komputer yang memungkinkan user (pengguna) untuk mendelegasikan tugas kepadanya secara mandiri (autonomously).Kemudian beberapa peneliti lain menambahkan satu hal lagi, yaitu bahwa agent harus bisa berjalan dalam kerangka lingkungan jaringan (network environment).

Pada hakekatnya daftar karakteristik dan atribut di bawah adalah merupakan hasil survei dari karakteristik yang dimiliki oleh agent-agent yang ada pada saat ini (Wahono, 2003):

1) Otonomi (Reagan, 2004).

2) Cerdas, Menalar, dan Belajar Mandiri

3) Mobilitas dan Statis (Nwana, 1996):

4) Delegasi

5) Ferber (Ferber, 1994 dalam Nwana, 1996)

6) Proaktif dan Berorientasi pada Tujuan

7) Komunikasi dan Kemampuan Koordinasi. Durfee (Durfee, 1987 dalam Nwana, 1996)

Metode yang digunakan ialah metode yang diperkenalkan oleh Wooldrige, Jennings dan Kinny (Wooldrige et.al, 1999). Metode ini memiliki dua tahap yaitu analisis dan desain.

Tahap ini terdiri dari langkah-langkah:

1). Tahap Analisis

1. Identifikasi Peran

2.Penyusunan Model Intraksi

2). Tahap Desain

3. Perancangan Model Agent

4. Menentukan Layanan (Service)

5.Mengembangkan Model Acquaintance

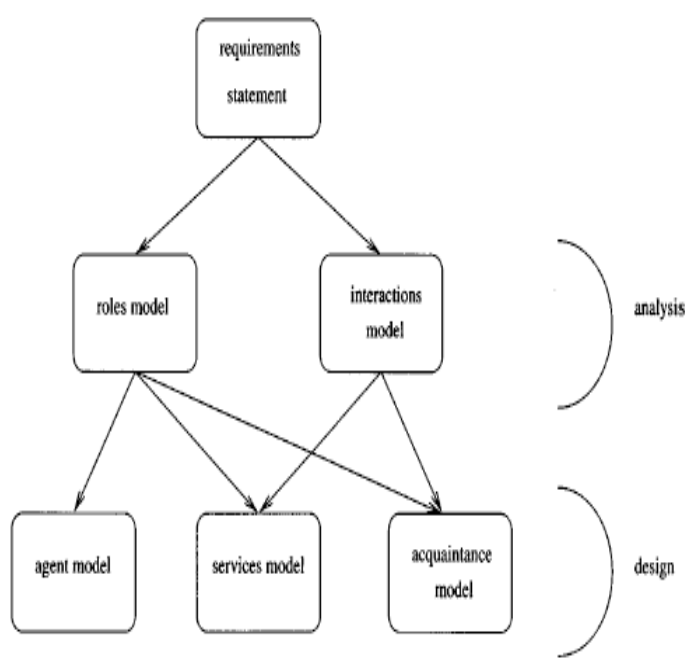

Gbr.1 Hubungan Antar Model

(Wooldrige et.al, 1999)

\section{Platform Aglet Server}

IBM Aglets SDK merupakan sebuah kumpulan Application Programming Interface (API) yang berisikan class - class dasar dalam pembentukan sebuah agent, sehingga tools ini akan sangat bermanfaat dalam proses pengembangan suatu sistem yang berbasiskan 
multi agent. IBM Aglets SDK memfokuskan diri pada karakteristik mobility agent, sehingga protokol - protokol dasar untuk

mobilisasi suatu agent sudah tersedia dengan baik dan sistematis, serta mudah untuk diimplementasikan (Ferrari, 2004).

Tahiti Server merupakan sebuah aglet server yang menjadi tempat hidup/singgah dari sebuah agent selama masa hidupnya. Versi terbaru tersedia secara gratis melalui: http://www.trl.ibm.co.jp/aglets/index.html.

Konsep Aglet terdiri dari Aglet, Proxy, Context dan Engine. Fungsi dari fitur-fitur tersebut diuraikan seperti dibawah ini:

- $\quad$ Aglet - merupakan obyek mobile Java

- Proxy - mewakili suatu aglet

- berfungsi sebagai security shield suatu aglet

- Mengontrol dan membatasi akses secara langsung ke suatu aglet

- Menyediakan transparansi lokasi bagi aglet

- Context - proses eksekusi environment bagi aglets

- Engine - suatu Java Virtual Machine (JVM) yang berjalan pada suatu host yang melayani satu atau lebih context.

- Disebut juga Aglet Server.

- Program agletsd digunakan untuk memulai Aglet Server pada spesifik port.

- Program agletsd digunakan juga untuk memulai Tahiti Aglets Viewer.

Operasi Aglet terdiri dari creations, cloning, dispatching, retraction, deactivation/activation, dan disposal.

Untuk menggambarkan operasi aglet dapat diperhatikan pada gambar 2. seperti di bawah:

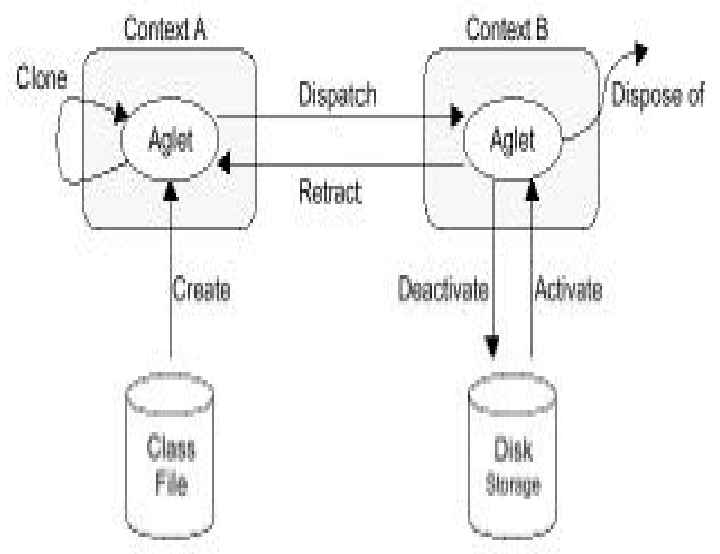

Gbr. 2 Diagram Aglet LifeCycle (Tar et.al, 2000)

\section{Identifikasi Proses Bisnis}

Dalam perkembangannya, PT. TNF mempunyai visi, misi dan tujuan sebagai berikut:

- Visi: mampu mensejajarkan diri sebagai salah satu industri terpercaya di Indonesia dalam bidang farmasi bagi kesejahteraan masyarakat.

- Misi: menghasikan produk-produk yang berkualitas tinggi dengan mengacu kepada Cara Pembuatan Obat yang Baik (CPOB) dan menerapkan teknologi modern serta dukungan tenaga-tenaga profesional yang handal.

- Tujuan: menyediakan solusi terbaik bagi kesehatan masyarakat secara umum dan keluarga berencana nasional secara khusus; menciptakan efisiensi, kefektifan dan koordinasi serta inovasi produk bagi daya saing produk unggulan yang bertaraf internasional.

Sedangkan untuk proses bisnis PT. TNF dijelaskan pada Gbr. 3 berikut ini:

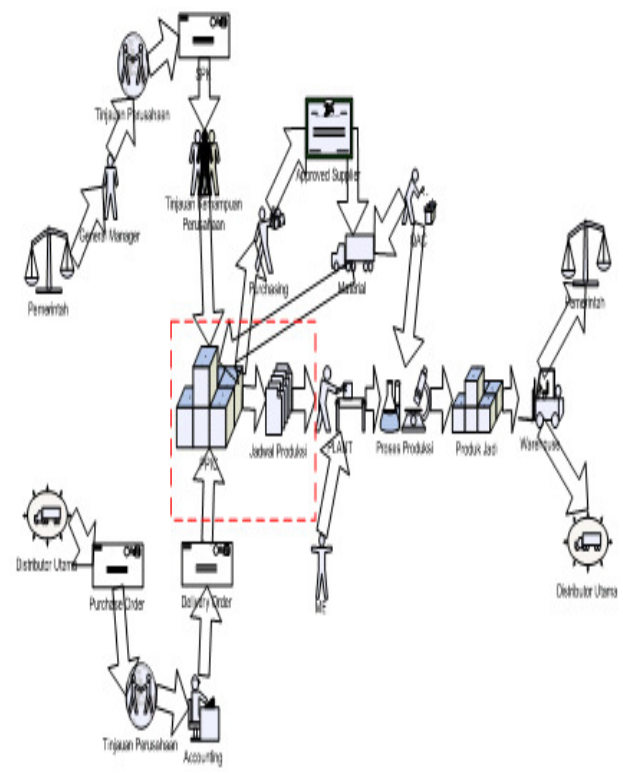

Gbr. 3 Proses Bisnis PT. TNF

\section{Perencanaan Sistem}

Langkah pertama dalam melakukan perancangan sistem informasi adalah planning (perencanaan), adalah tahapan awal suatu proses yang melandasi pemahaman tentang mengapa sistem informasi ini dibuat. Proses tahapan awal ini dimulai dari proses mengidentifikasi business value (manfaat bisnis) untuk memahami sejauh mana manfaat digunakannya sistem bagi perusahaan khususnya pada PT TNF. 
Berdasarkan hasil interview seperti yang tercantum dalam system request (lihat Tabel I) di bawah, mengenai kebutuhan untuk mengembangkan sistem informasi di PT TNF.

TABEL I

System Request

\begin{tabular}{|l|l|}
\hline $\begin{array}{l}\text {-Perancangan } \\
\text { Produksi- }\end{array}$ & \multicolumn{1}{l}{$\begin{array}{l}\text { Sistem Informasi (SI) Rendal } \\
\text {-berbasis Agent- }\end{array}$} \\
\hline $\begin{array}{l}\text { Project } \\
\text { Sponsor: }\end{array}$ & Manager Produksi \\
\hline Business Need: & $\begin{array}{l}\text { Mempercepat proses eksekusi } \\
\text { order, meningkatkan kemampuan } \\
\text { produksi, mengurangi kesalahan } \\
\text { instruksi operasi, terkendalinya stok } \\
\text { obat, mempermudah dokumentasi } \\
\text { sistem produksi, dan meningkatkan } \\
\text { koordinasi }\end{array}$ \\
\hline $\begin{array}{l}\text { Business } \\
\text { Requirement: }\end{array}$ & $\begin{array}{l}\text { Menyediakan SI Rendal Produksi, } \\
\text { mengintegrasikan aplikasi, dan } \\
\text { prosedur koordinasi aplikasi }\end{array}$ \\
\hline $\begin{array}{l}\text { Business } \\
\text { Value: }\end{array}$ & $\begin{array}{l}\text { Target stok tercapai, produksi dan } \\
\text { pengiriman tepat waktu, tidak ada } \\
\text { kesalahan instruksi pekerjaan, } \\
\text { peningkatan akurasi data \& } \\
\text { informasi antar unit }\end{array}$ \\
\hline $\begin{array}{l}\text { Special Issue } \\
\text { or Constraint }\end{array}$ & $\begin{array}{l}\text { Adanya komunikasi/ sosialisasi } \\
\text { dalam menerapkan sistem yang } \\
\text { inovatif ini agar pengguna siap }\end{array}$ \\
\hline
\end{tabular}

Setelah mengidentifikasi kebutuhan bisnis, maka dilanjutkan dengan membuat analisis feasibility untuk memberikan lebih jauh pemahaman akan peluang dan resiko pembuatan proyek ini terhadap kelangsungan bisnis perusahaan. Dalam tahapan ini dirangkum menjadi 3 aspek umum, yaitu: technical feasibility, economical feasibility dan organizational feasibility.

\section{Analisis Kebutuhan}

Dalam menganalisis sistem yang sedang berjalan di PT. TNF, dilakukan pengkajian mengenai analisis kebutuhan yang ada pada sistem pembangun produksi, kemudian memodelkan hasil analisis sistem ke dalam model fungsional dengan use case, kemudian model struktural dan dinamis yang dikembangkan dengan agent sehingga memudahkan perancangan sistem. (lihat Gbr. 4).

Berdasarkan justifikasi awal mengenai mengapa sistem informasi ini dibuat, maka dapat dirumuskan beberapa kebutuhan yang harus ada pada sistem yang baru adalah sebagai berikut: Kebutuhan sistem dalam basis teknologi mesin/alat, Kebutuhan sistem dalam organisasi produksi dan Kebutuhan sistem dalam teknik manajemen produksi

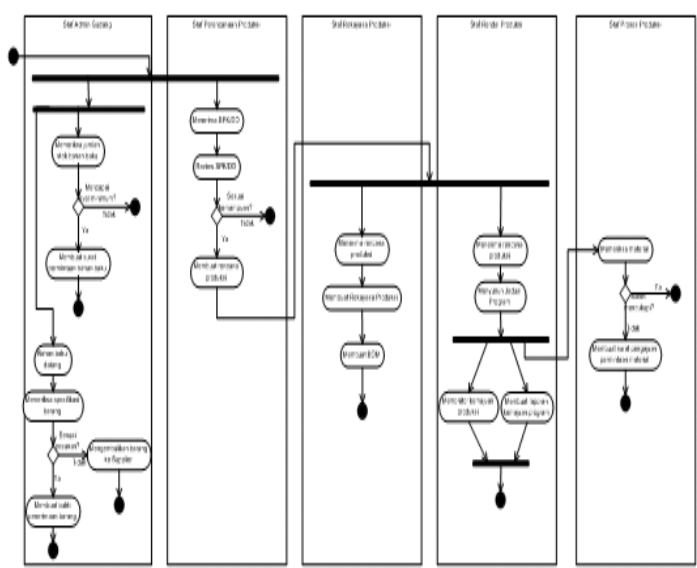

Gbr. 4 Activity Diagram Rendal Produksi saat ini

Langkah berikutnya di dalam analisis adalah membuat model fungsional dari proses bisnis yang telah digambarkan pada Gbr. 4, bertujuan untuk memahami kebutuhan dan perilaku sistem informasi baik itu yang telah ada sebelumnya maupun yang akan dibuat. Proses pengecekan material dilakukan oleh Staf Perencanaan Produksi secara fisik dengan langsung mendata persediaan barang di gudang, dan juga mengecek di database gudang. Pengecekan ganda ini merupakan salah satu kebijakan dari manajer PPIC, karena walaupun sistem database yang terkomputerisasi sudah diimplementasikan dan berjalan dengan rutin, tetapi masih ada kekhawatiran bahwa ada staf yang lupa memasukkan data setelah terjadinya transaksi obat, baik input maupun output, dan juga kebijakan ini adalah untuk prosedur pengamanan, sehingga bila ada data yang tidak sesuai dengan kenyataan, maka dapat langsung diganti. Hal ini disebabkan karena pada akhir bulan, pembuatan laporan inventori didasarkan pada data yang ada di database.

\section{Pemodelan Sistem yang Baru}

Pada sistem yang baru ini, terjadi beberapa penyederhanaan fungsi kerja akibat otomatisasi oleh sistem informasi. Hal ini menyebabkan peran/aktor yang terlibat mengalami penyederhanaan dari yang berjumlah lima peran menjadi tiga peran. Diharapkan pada sistem yang baru kelak hanya tiga peran dominan yang terlibat yaitu Staf PPIC, Staf Produksi dan Manajer Produksi. Untuk itu dibuat model use case dari sistem yang baru agar memberi pemahaman bagi stakeholder mengenai kemampuan sistem dalam berinteraksi dengan lingkungannya. (Gbr. 5) 


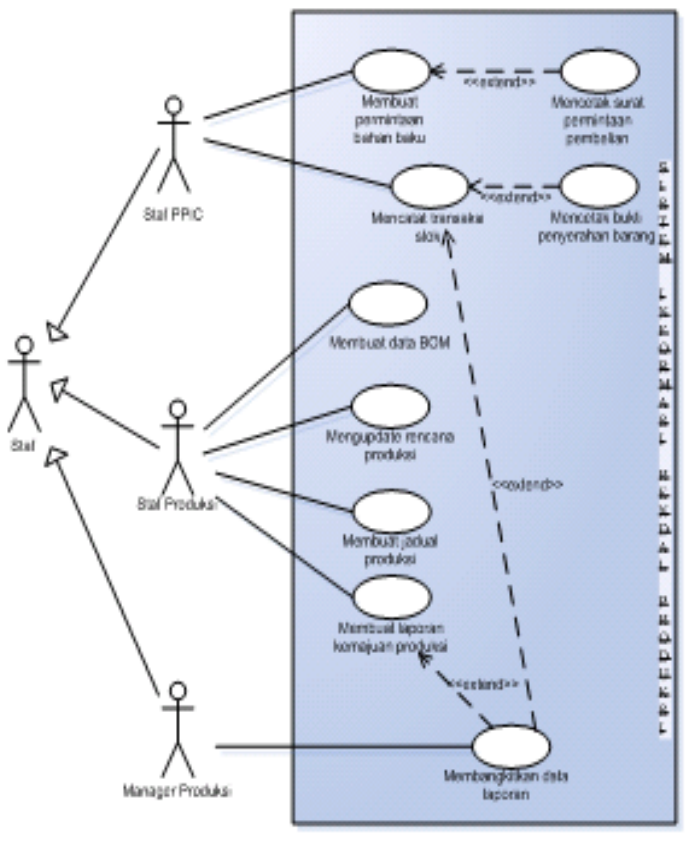

Gbr. 5 Use Case Diagram untuk Sistem yang Baru

\section{Kesimpulan}

Beberapa kesimpulan dari penulisan paper ini antara lain adalah:

1) Identifikasi proses bisnis sistem informasi harus dilakukan pada tahap awal dalam proses pengembangan sistem. Keterlibatan stakeholders bersifat mandatory.

2) Kakas UML versi 2.0 dapat digunakan untuk membantu proses pemodelan proses bisnis dan pendefinisian persyaratan sistem informasi.

\section{Referensi}

Bergenti, F., A. Poggi. Agent Oriented Software Construction with UML. Parco Area delle Scienze 18A Parma, Italy, 2000

Bradshaw, Jeffrey. Software Agents, Set of Journals, MIT Press, 1997

Caire, G., W. Coulier, F. Garijo, J. Gomez. Agent Oriented Analysis Using Message/UML. Telecom Italia LAB Turin, Italy, 2000

Dennis, A., H.W. Barbara, D. Tegarden. System Analysis and Design with UML version 2.0. John Wiley \& Sons, Inc, 2005

Feng, Shaw. Manufacturing Planning and Execution Software Interfaces. Manufacturing Engineering Laboratory, NIST Gaithersburg, Maryland, USA, 2000

Ferrari, Luca. Aglets 2.0.2 User Manual. IBM Tokyo Research Laboratory, 2004

Fu, Yonghui., R. Piplani. Multi-Agent Enabled
Modeling and Simulation Towards Collaborative Inventory Management in Supply Chains. School of Mechanical \& Production Engineering, Nanyang Tachnological University, Singapore, 2000

Herrmann, W. J. Improving Production Scheduling: Integration Organizational, Decision Making, and Problem Solving Perspektives. Departement of Mechanical Engineering and Institute for System Reasearch, University of Maryland, 2004

Hoog, de Robert., R. Martil, B. Wielinga, R. Taylor. The Common KADS Model Set. University of Amsterdam, 1994

Iglesias, C.A., M. Garijo, J. C. Gonzalez, J.R. Velasco. Analysis and Design of Multi Agent System using MAS-Common $K A D S$. Univ.de Valladoid, Valladoid, Spain, 1996

Jack, Hugh. Integration and Automation of Manufacturing Systems. U.K, 2001

Kuikka, Seppo. A Batch Process Management Framework: Domain specific, design pattern, and software component based approach. Technical Research Center of Finland, ESPOO 1999

Mochamad, Mas. Perancangan Prototip Perangkat Lunak Berbasis Sistem Multi Agent Sebagai Alat Bantu Penjadwalan Produksi di PT LEN Industri. Tugas Akhir Sarjana Jurusan teknik Industri. Institut Teknologi Bandung, 2004

Nwana, H.S. Software Agent: An Overview. Intelligent System Research AA\&T, BT Laboratories, Ipswich, Suffolk, U.K, 1996

Ouelhadj, Djamila. A Multi Agent System for The Integrated Dynamic Scheduling of Steel Production. The University of Nottingham, The School of Computer Science \& Information Technology, August 2003

Parunak, H.V.D., A.D. Baker, S.J. Clark. The AARIA Agent Archtecture: An Example of Requirements-Driven Agent-Based System Design. Center of Electronic Commerce, Industrial Technology Institute, 1997.

Pechoucek, M., A. Riha, J. Vokrinek. ExPlanTech: Applying Multi Agent Systems in Production Planning. Gerstner Laboratory, Departement of Cybernetics, Czech Technical University, 2001

Prasetyo, Kurniawan. Pola Rancangan Modul Inventory Control untuk Pengembangan 
Sistem Informasi Studi Kasus: Percetakan Offset PT XYZ. Program Magister Teknologi Informasi, Fakultas Ilmu Komputer, Universitas Indonesia, 2006

Reagan, J. Simulasi Sistem Pengendalian Level Dengan Pengendali Logika Fuzzy pada Stripper Accumulator di PT.Pertamina UP.V Balikpapan. Universitas Brawijaya, Malang, 2004

Splunter, V.S. Strategic Automated Agent Design. Master Thesis, Departement of Artificial Intelligence, Faculty of Science, Vrije Universiteit Amsterdam, 2002

Tarr, B., D. Nebesh, S. Foster. Introduction to Mobile Agent System and Applications.
Departement of USA, 2000

Wahono, Romi. Multi Agent System: Beberapa Isu, Pendekatan dan Tantangan. Departement of Information and Mathematical Sciences, Saitama University, 2001.

Wooldridge, M., N.R. Jennings, and D. Kinny. Gaia Methodology for Agent Oriented Analysis and Design. Kluwer Academic Publishers, 2000.

Zhang, T.I., E. Kendall, H. Jiang. An Agentoriented Software Engineering Methodology with Application of Information Gathering System for LCC. School of Network Computing, Monash University, Australia, 2000 